Original Article

\title{
EVALUATION OF RENAL PROTECTIVE ACTIVITY OF ADHATODA ZEYLANICA (MEDIC) LEAVES EXTRACT IN WISTAR RATS
}

\author{
Arunachalam Kumar ${ }^{1}$, Suchetha Kumari N. ${ }^{2}$, Prima D'Souza ${ }^{3}$ \& Divya Bhargavan ${ }^{4}$ \\ ${ }^{1}$ Professor of Anatomy, ${ }^{2}$ Professor of Biochemistry, ${ }^{3,4}$ Lecturers \\ ${ }^{1,3}$ Department of Anatomy, ${ }^{2}$ Department of Biochemistry \& ${ }^{4}$ Department of Pharmacology \\ K.S. Hegde Medical Academy, Nitte University Center for Science Education \& Research (NUCSER), \\ Mangalore - 575 018, India.

\section{Correspondence} \\ Arunachalam Kumar \\ Head, Department of Anatomy, Director (R\&D) Nitte University \\ K. S. Hegde Medical Academy, Mangalore - 575 018, India. \\ E-mail : directorrd@nitte.edu.in, editornujhs@nitte.edu.in
}

\section{Abstract :}

The kidney is especially a susceptible organ to toxic injuries by drugs and toxin, because of a high blood supply and the presence of cellular transport systems that cause accumulation of these compounds within the nephron epithelial cells. Glomerular, tubular and interstitial cells frequently encounter significant concentrations of medications and their metabolites, which can induce changes in kidney function and structure. Renal toxicity can be a result of hemodynamic changes, direct injury to cells and tissue, inflammatory tissue injury and/or obstruction of renal excretion.

Gentamicin is potent broad spectrum antibiotic therapeutic agent used in a number of infective conditions. Because of the obvious mediation of Reactive Oxygen Species in Gentamicin induced renal damage. Several antioxidant agents have been used to block Gentamicin nephrotoxicity.

There is a proven converse relationship between the consumption of antioxidant rich plants incidence of human diseases. A primary goal of this study is to present the scientific evidence for the use of common herb Adhatoda zeylanica as supplementary in the gentamicin treated acute renal failure (ARF) subjects. The beneficial effect of $A$. Zeylanica against gentamicin nephrotoxicity, possibly depends on its ability to scavenge the gentamicin induced free radicals.

This study demonstrates the effectiveness of the extract improved with the polarity of the solvents over a period of 10 days and the plant has the potential to ameliorate Gentamicin nephrotoxicity.

Keywords : nephrotoxicity, Adhatoda zeylanica, gentamicin, free radicals, histopathology

\section{Introduction :}

The kidney is an essential organ that plays a dominant role in homeostasis by excreting the metabolic waste products and excess necessary substances. It conserves necessary products depending on the needs of the body [1]. It is especially susceptible organ to toxic injuries because of high blood supply and presence of cellular transport

\begin{tabular}{|c|}
\hline Access this article online \\
\hline Quick Response Code \\
\hline
\end{tabular}

systems that causes accumulation of these compounds within the nephron epithelial cells [2]. Kidney disease is one of the commonest causes of hospitalization. Acute renal failures are common and serious problems having high morbidity and mortality rate [3]. Renal failure is a common clinical syndrome. It is defined as a rapid decline in renal function resulting in abnormal retention of serum creatinine and blood urea which must be excreted. The clinical manifestations of renal failure are the decline in glomerular filtration rate (GFR) and the inability of the kidney to excrete the toxic metabolic substances produced in the body. Effects on the kidney related to medications are, both common and expected, given the kidney's roles in plasma filtration and maintenance of metabolic homeostatis. The renal vascular bed is exposed to a quarter of resting cardiac output. As such glomerular, tubular and interstitial cells frequently encounter significant 
concentrations of medications and their metabolites, which can induce changes in kidney function and structure. Renal toxicity can be a result of hemodynamic changes, direct injury to cells and tissue, inflammatory tissue injury and/or obstruction of renal excretion. Markers of early injury are been investigated [4].

The toxicity of Gentamicin, a broad spectrum antibiotic, is believed to relate to generation of reactive oxygen species (ROS) in kidneys. Several reports have been documented the pathogenesis of aminoglycosides- induced renal tubular cell injury such as derangement of lysosomal, mitochondrial and plasma membrane structure. Furthermore results of many studies have been shown that the altered concentrations of various biochemical indicators of oxidative stress in kidney tissue are due to Gentamicin. Because of the obvious mediation of ROS in Gentamicin induced renal damage. Several antioxidant agents have been used to block Gentamicin nephrotoxicity $[5,6,7]$.

Medicinal plants are commonly used in treating or preventing specific ailments or diseases and are considered to play a beneficial role in health care. Therefore, the study of plants as a resource of medicine has become more important in the context of present global trade scenario where oxidative stress is found to be one of the major causes of health hazards. India is considered as a treasure house of valuable medicinal and aromatic plant species.

Free radicals are highly reactive substances formed in the body as a result of metabolic processes. Many of these molecular species are oxygen (and sometimes nitrogen) centered free radicals and its non radical products. The term "reactive oxygen species" (ROS) collectively denotes oxygen centered radicals (super oxide and hydroxyl radicals) as well as non-radical species derived from oxygen such as hydrogen 1 peroxide ( $\mathrm{HO}$ ), singlet oxygen ( $\mathrm{O}$ ) and hypochlorous $(\mathrm{HOCl})$ acid [9]. The increased production of ROS seems to accompany most forms of tissue injury. Free radicals can also react with DNA, proteins or lipids in the cell membrane and cause damage [10]. The involvement of
ROS in aging and in many chronic diseases has been considered. The defense provided by antioxidant systems is crucial for the survival of organisms. Detoxification of ROS in the cell is provided by both enzymatic and non enzymatic systems which constitute the antioxidant defense systems. These antioxidants play a role in delaying, intercepting, or preventing oxidative reactions catalyzed by free radicals.

Many plants contain antioxidant compounds and these compounds protect cells against the damaging effects of reactive oxygen species (ROS) such as singlet oxygen, superoxide, peroxyl radicals, hydroxyl radicals and peroxynitrite. Thus compounds or antioxidants that can scavenge free radicals have vital role in improvement of diseased conditions [11]. Medicinal, herbal and aromatic plants constitute a large segment of the flora, which provide raw materials for use by pharmaceutical, cosmetic, fragrance and flavour industries.

Several studies have demonstrated a converse relationship between the consumption of antioxidant rich plants or vegetables and the incidence of human diseases. There is emerging evidence in the literature about renoprotective complementary and alternative medicines. A primary goal of this study is to present the scientific evidence for the use of herb Adhatoda zeylanica as a complementary treatment for acute renal failure (ARF).

Adhatoda zeylanica is found throughout India up to an altitude of $1300 \mathrm{~m}$. It is a Perennial, evergreen shrub, 1.2 $2.5 \mathrm{~m}$ high. The leaves leathery and lowers are white with red or yellow barred throats, in spikes with large bracts. Capsules are clavate, longitudinally channeled, $1.9-2.2 \mathrm{~cm}$ long. Seeds are globular.

The plant's root, leaf, flower, fruit are used for therapeutically. A. zeylanica has been frequently used for the treatment of respiratory complaints and for cough, asthma and colds [12]. It is used as an expectorant, bronchodilator and to liquefy sputum $[13,14,15,16,17)$. A. zeylanica as an expectorant and antispasmodic agent was described and an alkaloid with a bitter taste was identified and named vasicine $[18,19]$. The macerated 
roots of the Vasak (A. zeylanica) are applied on the pubic region and the vagina to help parturition $[20,21]$ stated the use of the whole plant of $A$. zeylanica for treating impotence and sexual disorders. The use of A. zeylanica leaves for checking postpartum haemorrhage in intermittent, typhus fevers, febrifuge and diphtheria is been reported. [22]. It is also used for stomach catarrh with constipation, rheumatism, gout, and urinary stone [23]. Leaf powder boiled in sesame oil is used to stop bleeding, ear aches, and pus from ears [24]. Root decoction is used for gonorrhoea [25]. Water extract of leaf is used to relieve acidity [26]. Leaf is used for urinary trouble.

Arun Yadav et al [27] studied anticestodal efficacy of Adhatoda vasica leaf extract using Hymenolepis diminutarat experimental model. The result indicated that $800 \mathrm{mg} / \mathrm{kg}$ double dose of extract has profound efficacy against mature worms. The study showed that the leaf extract of possesses significant anticestodal efficacy and supports its use in the folk medicine.

Meenal Kumar et al [28] have reported that the modulator effect of ethanolic extract of $A$. vasica (L) Nees against radiation-induced changes in terms of histological alterations in testis, reduced glutathione (GSH), lipid peroxidation (LPO), acid and alkaline phosphatases levels, and chromosomal alterations in Swiss albino mice was studied at various post-irradiation intervals between 1 and 30 days. When ethanolic leaf extract of $A$. vasica was given orally at a dose of $800 \mathrm{mg} \mathrm{kg}^{-1}$ body weight per mouse for 15 consecutive days and then exposed to radiation, death of Adhatoda-pretreated irradiated mice was reduced to $70 \%$ at 30 days. The study suggested that Adhatoda plant extract has significant radioprotective effects on testis that warrants further mechanistic studies aimed at identifying the role of major ingredients in the extract.

Avula et al [29] developed a new method of capillary electrophoresis for the quantitative determination of vasicine and vasicinone from Adhatoda vasica (L.) Nees. The electrophoretic separation was performed using fused silica capillary. The samples were injected by pressure for $3 \mathrm{~s}$ at 50 mbar and the running voltage was $19 \mathrm{kV}$ at the injector end of the capillary. The capillary temperature was maintained at $40^{\circ}$ C. The separation of the two alkaloids has been achieved within 11 min with good repeatability. The method was validated in terms of reproducibility, linearity, accuracy and applied for the quantitative determination of vasicine and vasicinone in $A$. vasica plant samples/extracts. Parameters affecting the resolution such as $\mathrm{pH}$, temperature, organic modifier, buffer concentration and capillary dimensions were reported.

Kumar et al [30] studied the radiomodulatory influence of ethanolic extract of Adhatoda vasica Nees leaf extract against radiation-induced hematological alterations in peripheral blood of Swiss albino mice was studied at various post-irradiation intervals between $6 \mathrm{~h}$ to 30 days. Oral administration of A. vasica leaf extract $(800 \mathrm{mg} / \mathrm{kg}$ body weight) prior to whole body irradiation showed a significant protection in terms of survival percentage and hematological parameters. Animals pre-treated with $\mathrm{A}$. vasica leaf extract showed $81.25 \%$ survival till 30 days after exposure and a gradual recovery was noted in the hematological values. A significant decrease in blood reduced glutathione (GSH) content and increase in lipid peroxidation (LPO) level was observed in control animals (Radiation alone). However, A. vasica leaf extract pretreated irradiated animals exhibited a significant increase in GSH content and decrease in LPO level. A significant increase in the serum alkaline phosphatase activity and decrease in acid phosphatase activity was observed in A.vasica leaf extract pretreated irradiated animals during the entire period of study.

Vinothapooshan et al [31] made a study on methanolic, chloroform, and diethyl ether extracts of leaves of Adhatoda vasica at the dose of $200 \mathrm{mg} / \mathrm{kg}$ body weight per oral and studied for the hepatoprotective effect using Carbontetrachloride induced liver damage in wistar albino rats. Methanolic extract showed significant $(p<0.05)$ hepatoprotective effect. The experimental results suggests that the biologically active phytoconstituents such as Alkaloids- Quinazoline, Flavonoids, Tannins, Vasicinone, Essential oil present in the various extracts of Adhatoda 
vasica plant may be responsible for the significant hepatoprotective activity and the results justify the use of Adhatoda vasica as a hepatoprotective agent.

Shirish et al [32] carried out a work to investigate the potential hepato-protective action of Adhatoda vasica whole plant powder against $\mathrm{CCl} 4$ induced liver damaged Wister rat model. Blood and tissue biochemical parameters of liver were examined for evaluating the hepatoprotection action. These biochemical markers are GOT, GPT, Alkaline phosphate, glucose, bilirubin, Triglycerides, ?GT, cholesterol, DNA, RNA, total protein etc, The effect of Adhatoda vasica whole plant powder is compared with Silymarin by standard protocol and is found to have better hepatoprotective action, thus Adhatoda vasica indicating protection in liver may prove promising effect against liver disorders. Thus it may act even in humans as a potent liver tonic.

\section{Gentamicin nephrotoxicity}

Wellwood et al [33] carried out a study to see the effect of Gentamicin on kidneys. Gentamicin was administered to male Wistar rats by intramuscular injection at varying dosage and for varying periods. At dosages equivalent to that given to man ( $5 \mathrm{mg} / \mathrm{kg} /$ day) obvious degenerative changes are produced. Proximal tubular, epithelial cell damage varied from cytoplasmic inclusion of lipid and laminated bodies at low dosage to tubular necrosis at high dosage (50-100 mg/kg/day), there is increased excretion of urinary enzymes proportional to the degree of tubular damage.

Moir et al [34] did a study to see the effect of Gentamicin on kidneys. Gentamicin was administered to male Wistar rats by intramuscular injection at varying dosage and for varying periods. At dosages equivalent to that given to man (5 $\mathrm{mg} / \mathrm{kg} /$ day) obvious degenerative changes are produced. Proximal tubular, epithelial cell damage varied from cytoplasmic inclusion of lipid and laminated bodies at low dosage to tubular necrosis at high dosage (50-100 $\mathrm{mg} / \mathrm{kg} /$ day), There is increased excretion of urinary enzymes proportional to the degree of tubular damage .
Porter GA et al [35] reported a study done on Gentamicin induced Nephrotoxicity. The autoradiography of microdissected isolated nephrons, showed that Gentamicin distributes almost exclusively in the proximal tubule, where an increasing concentration gradient takes place from the initial to the distal part. On isopycnic centrifugation of homogenates from isolated tubules, the drug is found exclusively associated with the lysosomes 6 hours after injection. At a shorter time, the distribution is slightly bimodal and consistent with an association of part of the drug with brush border. This agrees with the suggestion that Gentamicin enters cells and accumulates in lysosomes by absorptive pinocytosis. In Gentamicintreated animals, it showed (1) a decrease of the latency of lysosomes; (2) a decrease of the activity of lysosomal sphingomyelinase and, at large doses, of cathepsin B and aD-galactosidase;(3) a decrease of the activity of alanylaminopeptidase and y-glutamyl-transpeptidase. Unlike the others, the latter effect is not dose-related. All these alterations showed complete reversibility within 15 to 21 days after gentamicin withdrawal. These findings are consistent with the proposal that a central feature of the mechanism of Gentamicin nephrotoxicity involves the accumulation of the drug in the lysosomes of the cells of the proximal tubule, leading to an extensive dysfunction of these cells. From in vitro studies on cultured cells (fibroblasts), these alterations of the cell metabolism seem to be relevant for cell necrosis and cell death.

Pramila Padmini et al [36] have performed combined in vivo and in vitro measurements of thymidine uptake into kidney cortex DNA of animals treated with Gentamicin for 7 days at 10 or $20 \mathrm{mg} / \mathrm{kg}$ daily (BID). Labelled thymidine was taken up by cortex fragments in vitro (90 min incubation) and incorporated into DNA; treatment of the animals with Gentamicin results in a significant dose-dependent enhancement of this in vitro thymidine incorporation; labeled cells were found primarily in the proximal tubules and interstitium; there is an excellent correlation ( $r: 0.983$, $n=15$ ) between the changes of incorporation measured in vivo and in vitro as demonstrated by the sequential use of $[3 \mathrm{H}]$ thymidine (in vivo) and [14C] thymidine (in vitro) 
within the same animals.

Pratibha Singh et al [37] study said that Drug-induced nephrotoxicity is an important cause of renal failure. Aminoglycosides throughout the endocytic pathway are taken up into the epithelial cells of the renal proximal tubules and stay there for a long time, which leads to nephrotoxicity. Tubular epithelial necrosis and dilatation was observed effecting less than half of cortical tubules when rats treated with $60 \mathrm{mg} / \mathrm{kg}$ b.w. Hyaline cast formation was observed in PCT with atrophic glomeruli effecting half of the cortical region when rats treated with $80 \mathrm{mg} / \mathrm{kg}$ b.w. Gentamicin must be given in the lowest effective therapeutic doses in patients with normal kidney function

Laxmi et al [38] aimed at evaluating the ethanolic and aqueous extracts of root of Bauhinia variegata Linn. for antioxidant and nephroprotective effect in Gentamicininduced nephrotoxicity in rats. The antioxidant activity of both ethanolic and aqueous extracts of root of Bauhinia variegata Linn was carried out. Nephrotoxicity was induced in Wistar rats by intraperitoneal administration of gentamicin $100 \mathrm{mg} / \mathrm{kg} /$ day for eight days. Ethanolic and aqueous extracts of the root of Bauhinia variegata Linn. At dose of 200 and $400 \mathrm{mg} / \mathrm{kg}$ b.w. were concurrently given by oral route. Serum creatinine, serum urea, urine creatinine and blood urea nitrogen (BUN) were determined on day 9 . Histopathological study of kidney was also done. Both ethanolic and aqueous root extracts of Bauhinia variegata Linn. produced significant free radical scavenging activity. Both the extracts produced significant nephroprotective activity in Gentamicin induced nephrotoxicity model as evident by decrease in elevated serum creatinine, serum urea, urine creatinine and BUN levels, which was further confirmed by histopathological study. Gentamicin induced glomerular congestion, blood vessel congestion, and epithelial desquamation, accumulation of inflammatory cells and necrosis of the kidney cells were found to be reduced in the groups receiving the root extract of Bauhinia variegata Linn., along with Gentamicin .

Rama Saha1 et al[39] made a study to evaluate the effect of ethyl acetate extract of fresh rhizomes of Zingiber officinale and dried fresh juice of fresh rhizomes for its protective effect on Gentamicin induced nephrotoxicity in rats. Nephrotoxicity was induced in wistar rats by intraperitoneal administration of Gentamicin $100 \mathrm{mg} / \mathrm{kg}$ for eight days. Effect of concurrent administration of ethyl acetate extract and fresh juice extract of Zingiber officinale at a dose od $200 \mathrm{mg} / \mathrm{kg}$ given by oral route was determined using serum creatinine, serum uric acid, blood urea nitrogen and serum urea as indicators of kidney damage. The study groups contained six rats in each group. It was observed that the ethyl acetate and fresh juice extract of Zinger officinale significantly protect rat kidneys from Gentamicin-induced histopathological changes.

Okokon J et al [40] had done a study to observe the toxic effect of gentamicin on epithelial cells of proximal convoluted tubule in Long Evans rats. Eighteen mature long Evans rats were divided into three groups A, B \& C. The rats of group A were treated with vehicle and group $B$ and $C$ were treated with gentamicin $50 \mathrm{gm}$ and $100 \mathrm{gm}$ respectively. Blood urea and serum creatinine were measured and microscopic damaged cells were counted. There was significant increase in serum creatinin and blood urea in gentamicin treated groups. Microscopic examination of kidney showed necrosis of proximal tubular cells. It can be concluded from this study that gentamicin has toxic effects on renal tubule.

Hussain $T$ et al [41] had done a study to evaluate the protective effect of ethanolic root extract of Croton zambesicus (C. zambesicus) against gentamicin-induced kidney injury in rats. The root extract $(27-81 \mathrm{mg} / \mathrm{kg}$ ) was administered to rats for eight days with concurrent administration of gentimicin $(100 \mathrm{mg} / \mathrm{kg}$ ) daily for the same period of time. Protective effect of the extract was evaluated in serum levels of creatinine, urea, and uric acid as well as some ions like sodium, potassium and chloride. Histological examination of the kidneys from different treatment groups were also carried out. Administration of the root extract significantly reduced histopathological changes in the kidneys of the extract-treated rats especially 
in the rats treated with lower doses of the extract (27 and $54 \mathrm{mg} / \mathrm{kg}$ ). The levels of serum urea and creatinine were also reduced significantly $(P<0.01)$ at these doses with no observable effect on the levels of uric acid and ions. The kidney - protective activity of this extract could be due to its antioxidant and free radical scavenging activities. [41]

\section{Materials and methods :}

Extract: The leaves of Adhatoda zeylanica were collected during the month of September from Mangalore region, cleaned and coarsely powdered and used for the extraction purpose. $80 \mathrm{gms}$. of powdered material was evenly packed and thimble was prepared and extraction was carried out with ethanol (60-80 0C), for $72 \mathrm{~h}$ using a Soxlet apparatus. After extraction, the defatted extract was filtered through Whatmann filter paper (No. 10) to remove insoluble particles. The extract was evaporated using rotary evaporator until all solvent was removed. Dark greenish coloured extract was obtained.

Antioxidant Activity; DPPH radical scavenging assay: Antioxidants react with DPPH, a stable free radical which is reduced to DPPH-H and as a consequence the absorbance is decreased from the DPPH radical to the DPPH-H form. The degree of discolouration indicates the scavenging potential of the antioxidant compounds or extracts in terms of hydrogen donating ability.

The free radical scavenging capacity of the Adathoda zeylanica leaves ethanolic extract was determined using DPPH according to the method of Blois.[42] DPPH solution $(0.004 \% \mathrm{w} / \mathrm{v})$ was prepared freshly in $99 \%$ ethanol and was added to sample solutions $100 \mu \mathrm{g} / \mathrm{ml}$ in ethanol. The mixture was allowed to stand at room temperature in dark for 20 mins. Then the mixture was vortexed and the absorbance was read at $517 n m$ using a spectrophotometer. Ellagic acid was used as a reference standard. Control sample was prepared containing the same volume without any extract and $99 \%$ ethanol was used as blank. Lower absorbance of the reaction mixture indicated higher free radical scavenging activity. All tests were performed in duplicates. Percentage scavenging of the DPPH free radical was measured using the following equation, DPPH radical scavenging activity (\%) = (Acontrol-ATest)/Acontrol X 100, where A control is the absorbance of the control reaction and $A$ test is the absorbance in the presence of the extracts or standard.

Hydroxyl radical scavenging assay: This assay, as described by Elizabeth and Rao [43] was used with a slight modification. The assay is based on quantification of the degradation product of 2-deoxyribose by condensation with TBA. Hydroxyl radical was generated by the $\mathrm{Fe}^{3+}$ ascorbate-EDTA- $\mathrm{H}_{2} \mathrm{O}_{2}$ system (the Fenton reaction). The reaction mixture contained, in a final volume of $1 \mathrm{ml}, 2$ deoxy-2-ribose (2.8 mM); $\mathrm{KH}_{2} \mathrm{PO}_{4}-\mathrm{KOH}$ buffer (20 mM, pH 7.4); $\mathrm{FeCl}_{3}(100 \mu \mathrm{M}) ; \operatorname{EDTA}(100 \mu \mathrm{M}) ; \mathrm{H}_{2} \mathrm{O}_{2}(1.0 \mathrm{mM})$; ascorbic acid $(100 \mu \mathrm{M})$ and various concentrations (0-200 $\mu \mathrm{g} / \mathrm{ml}$ ) of the test sample or reference compound. After incubation for $1 \mathrm{~h}$ at $37^{\circ} \mathrm{C}, 0.5 \mathrm{ml}$ of the reaction mixture was added to $1 \mathrm{ml} 2.8 \%$ TCA, then $1 \mathrm{ml} 1 \%$ aqueous TBA was added and the mixture was incubated at $90^{\circ} \mathrm{C}$ for $15 \mathrm{~min}$ to develop the color. After cooling, the absorbance was measured at $532 \mathrm{~nm}$ against an appropriate blank solution. Reaction mixture without test substances/extracts was used as control. All tests were performed in duplicates. Ellagic acid, a classical OH scavenger, was used as a positive control. Lower absorbance of the reaction mixture indicated higher $\mathrm{OH}$ radical scavenging activity. Percentage inhibition was evaluated by comparing the test and blank solutions. Percentage scavenging of the $\mathrm{OH}$ radical was measured using the following equation, $\mathrm{OH}$ radical scavenging activity $(\%)=($ Acontrol-ATest $) /$ Acontrol X 100 . Where Acontrol is the absorbance of the control reaction and $A$ test is the absorbance in the presence of the sample of the extracts.

Reducing power (FRAP) assay: The $\mathrm{Fe}^{3+}$ reducing power of the extract was determined by the method of Oyaizu [44] with a slight modification. Different concentrations $(0$ $400 \mu \mathrm{g} / \mathrm{ml})$ of the extract $(0.5 \mathrm{ml})$ were mixed with $0.5 \mathrm{ml}$ phosphate buffer $(0.2 \mathrm{M}, \mathrm{pH} 6.6)$ and $0.5 \mathrm{ml}$ potassium hexacyanoferrate $(1 \%)$, followed by incubation at $50^{\circ} \mathrm{C}$ in a water bath for 20 min.After incubation, $0.5 \mathrm{ml}$ of TCA (10\%) was added to terminate the reaction. The upper portion of 
the solution $(1 \mathrm{ml})$ was mixed with $1 \mathrm{ml}$ distilled water, and $0.1 \mathrm{ml} \mathrm{FeCl}{ }_{3}$ solution (0.1\%) was added. The reaction mixture was left for $10 \mathrm{~min}$ at room temperature and the absorbance was measured at $700 \mathrm{~nm}$ against an appropriate blank solution. All tests were performed in duplicates. A higher absorbance of the reaction mixture indicated greater reducing power. Ellagic acid was used as a positive control.

Experimental Animal: Albino rats (Wistar strain) of either sex (150-200gms) and of approximately the same age and weight were procured from KSHEMA Animal House were used for the study. They were kept in animal caging system and provided with standard animal feed pellets and water ad libitum. Animals were randomly selected for different experimental groups and used for the in vivo determination of nephroprotective activity. All experiments were performed according to the norms of the ethical committee.

Acute toxicity studies: Acute toxicity studies for ethanolic extracts of Adathoda zeylanica was conducted as per OECD guidelines 423 using albino Wistar rats. Each animal was administered the extract by oral route at the doses from 100 to $5000 \mathrm{mg} / \mathrm{kg}$. The animals were observed for any changes continuously for the first $2 \mathrm{~h}$ and up to $24 \mathrm{~h}$ for mortality.

Evaluation of nephroprotective activity in Gentamicin induced nephrotoxicity: Experimental animals were distributed randomly, in three groups, containing six animals each.

Group I - Animals were administered with equivalent volumes of $0.1 \mathrm{ml}$ i.p of normal saline $(0.9 \% \mathrm{w} / \mathrm{v} \mathrm{Nacl})$ for 8 days.

Group II - Animals received $80 \mathrm{mg} / \mathrm{kg}$ body weight Gentamicin intraperitoneally for 8 days to induce nephrotoxicity.

Group III - Animals were received $80 \mathrm{mg} / \mathrm{kg}$ body weight of Gentamicin intraperitoneally for 8 days to induce Nephrotoxicity and $500 \mathrm{mg} / \mathrm{kg}$, of ethanolic leaf extract
Adathoda zeylanica was given respectively to the animals from 9 th to 18 th day of study.

Sample Collection: Individual rats belonging to different groups were placed in metabolic cages over a period of $24 \mathrm{~h}$ and urine was collected. At the end of the experiment, i.e. 24 hours after the last dose rats were anesthetized with chloroform. Blood samples were collected by cardiac puncture in plain plastic tubes, left to stand at for 1 hour, and centrifuged ( $900 \times \mathrm{g}$ for $15 \mathrm{mins}$ ) to separate serum. The serum obtained was stored at $-5^{\circ}$ Cuntil analysis.

Biochemical Analysis: Serum was analyzed for creatinine, urea and total protein using Agappe diagnostic kits.

\section{Parameters assessed for renal function:}

I) Body weight: The weight (in grams) of the animals was noted on the first and last day of treatment.

ii) Serum urea: Urea concentration in urine was estimated by Modified Berthelot methodology.

iii) Serum creatinine: Creatinine level in serum was estimated by Modified Jaffe's method.

iv) Serum protein: Total protein in serum was estimated by Direct Biuret method.

Histopathological studies: After blood sampling for the biochemical analysis, the animals were sacrificed quickly, dissected and small slices of kidney will be taken and fixed in $10 \%$ formalin. The specimens are dehydrated in ascending grades of ethanol, cleared in xylene and embedded in paraffin wax. Sections of $6 \mu \mathrm{m}$ in thickness are prepared and stained with Haematoxylin and Eosin then examined under microscopy

\section{Results :}

Antioxidant property: DPPH radical scavenging assay: DPPH test provides simplified version to detect the antioxidant properties of various molecules present in the extracts. A DPPH solution is decolorized when the odd electron becomes paired off in the presence of a free radical scavenger. The color becomes light yellow from deep violet. The results of the assay are given in the table1. The percentage of radical scavenging property of the 
extract and standard in this assay were $42.08 \pm 1.11 \%$ and $93.70 \pm 0.70 \%$ at $100 \mu \mathrm{g} / \mathrm{ml}$ respectively.

Hydroxyl radical scavenging assay: This assay shows the abilities of the extract and standard Ellagic acid to inhibit hydroxyl radical-mediated deoxyribose degradation in a $\mathrm{Fe}^{3+}$-EDTA-ascorbic acid and $\mathrm{H}_{2} \mathrm{O}_{2}$ reaction mixture. The results are shown in table 1 . The percentage of radical scavenging property of the extract and standard in this assay were $32.25 \pm 1.82 \%$ and $88.79 \pm 0.70 \%$ at $200 \mu \mathrm{g} / \mathrm{ml}$ respectively.

Reducing power assay: The extract showed potent antioxidant power by reducing power ability. The $\mathrm{EC}_{50}$ value of the extract and standard were found to be $775.66 \pm 0.67 \mu \mathrm{g} / \mathrm{ml}$ and $104.88 \pm 0.92 \mu \mathrm{g} / \mathrm{ml}$ respectively. Results of reducing power assay are shown in Table 1. .

Table 1: Comparison of radical scavenging property and reducing property of Adathoda zeylanica leaves ethanolic extract with Ellagic Acid

\begin{tabular}{lccc}
\hline & DPPH radical scavenging capacity & OH radical scavenging capacity & FRAP Assay \\
\hline & \% of radical scavenging & $\%$ of radical scavenging & EC50 \\
Property $/ 100 \mu$ g of extract & property $/ 200 \mu$ g of extract & conc. $\mu \mathrm{g} / \mathrm{ml}$ \\
A.zeylanica & $42.08 \pm 1.11 \%$ & $32.25 \pm 1.82 \%$ & $775.66 \pm 0.67$ \\
Extract & $93.70 \pm 0.70 \%$ & & \\
Ellagic Acid & P & $88.79 \pm 0.70 \%$ & $104.88 \pm 0.92$ \\
\hline
\end{tabular}

$\mathrm{P}<0.05$ is statistically significant. Data are expressed as Mean $\pm \mathrm{SD}$.

All three methods to estimate Antioxidant activity of the ethanolic extracts of leaves of Adhatoda zeylanica have proven the effectiveness compared to the reference standard ellagic acid.

\section{Toxicity studies:}

The ethanolic leaf extract of Adathoda zeylanica when orally given to the rats at doses from 1000 to $5000 \mathrm{mg} / \mathrm{kg}$ showed no mortality or any adverse signs with regard to body weight, body temperature, and food and water uptake during the first $2 \mathrm{~h}$ and no mortality was observed till $24 \mathrm{hr}$.Extract was safe upto a maximum dose of $5000 \mathrm{mg} / \mathrm{kg}$ b.w. the dosage for further pharmacological study was fixed at $250 \mathrm{mg} / \mathrm{kg}$ b.w by oral route

Change in body weight: Gentamicin treated animals (Group II) showed a decrease in body weight compared to control rats (Group I) .There was an increase in body weight of animals treated with Ethanolic extract of Adathoda zeylanica respectively, when compared with Group II.

\section{Effect of test drug on Gentamicin induced nephrotoxicity}

Serum urea: Serum urea in the control group was estimated to be $30 \pm 2.302 \mathrm{mg} / \mathrm{dl}$. In the negative control group treated with Gentamicin only at the dose of $80 \mathrm{mg} / \mathrm{kg}$, it was $140.267 \pm 8.214$. In the post-treated group in which animals received Gentamicin along with plant extract at the dose of $500 \mathrm{mg} / \mathrm{kg}$ demonstrated a decrease in serum urea from $140.267 \pm 8.21 \mathrm{mg} / \mathrm{dl}$ to $59.40 \pm 10.09$ $\mathrm{mg} / \mathrm{dl}$ as compared with the negative control group $(P<0.01)$. Results are summarized in figure $1 \mathrm{~A}$.

Serum creatinine: Serum creatinine in plain control group was $0.7571+0.10 \mathrm{mg} / \mathrm{dl}$, whereas in negative control group, it increased to $2.443 \pm 0.30 \mathrm{mg} / \mathrm{dl}$. The post treated group showed significant decrease in serum creatinine from $2.443 \pm 0.308 \mathrm{mg} / \mathrm{dl}$ to $0.746 \pm 0.050 \mathrm{mg} / \mathrm{dl}$ as compared with negative control group $(P<0.001)$. Results are represented graphically in figure 1B.

Serum protein: Serum protein in plain control group was $4.72+0.07 \mathrm{mg} / \mathrm{dl}$, in Gentamicin treated negative control group it was recorded as $7.44 \pm 1.723 \mathrm{mg} / \mathrm{dl}$. In the posttreated group there was significant decrease in serum protein level from $7.44 \pm 1.723 \mathrm{mg} / \mathrm{dl}$ to $6.436 \pm 0.219$ $\mathrm{mg} / \mathrm{dl}$ as compared with negative control group $(\mathrm{P}<0.001)$. Results are graphically represented in figure $1 \mathrm{C}$.

In this study Serum creatinine, serum urea, serum protein were found to be significantly $(P<0.001)$ increased in rats treated with only gentamicin, whereas treatment with ethanolic extracts of leaves of Adhatoda zeylanica, reversed the effect of gentamicin indicating nephroprotective activity. 
Figure $1 \mathrm{~A}$

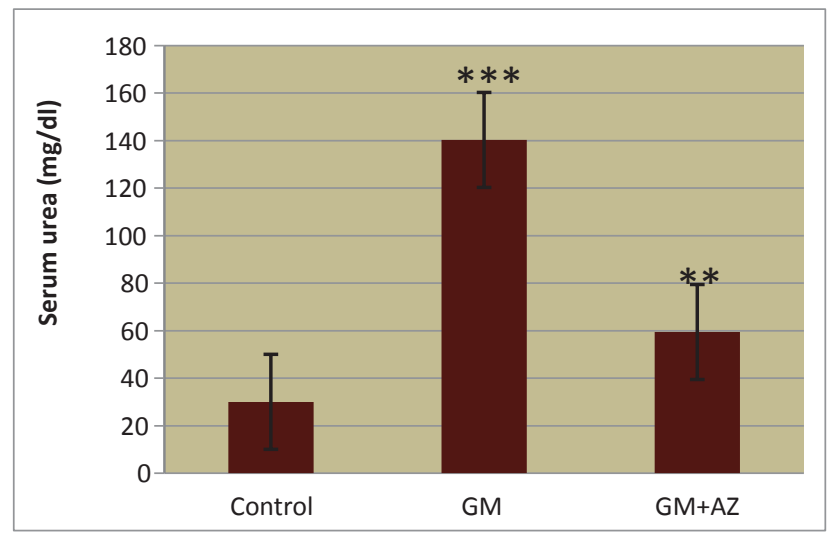

Figure $1 \mathrm{C}$

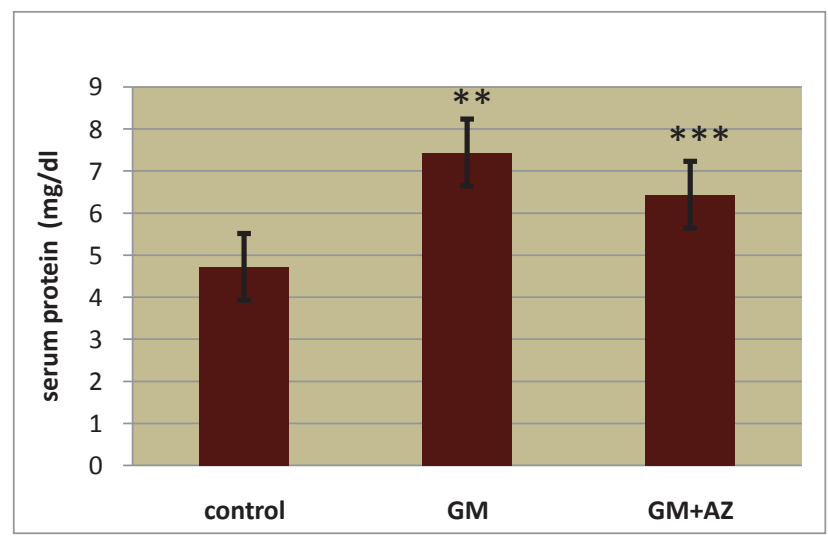

Figure $1 \mathrm{~B}$

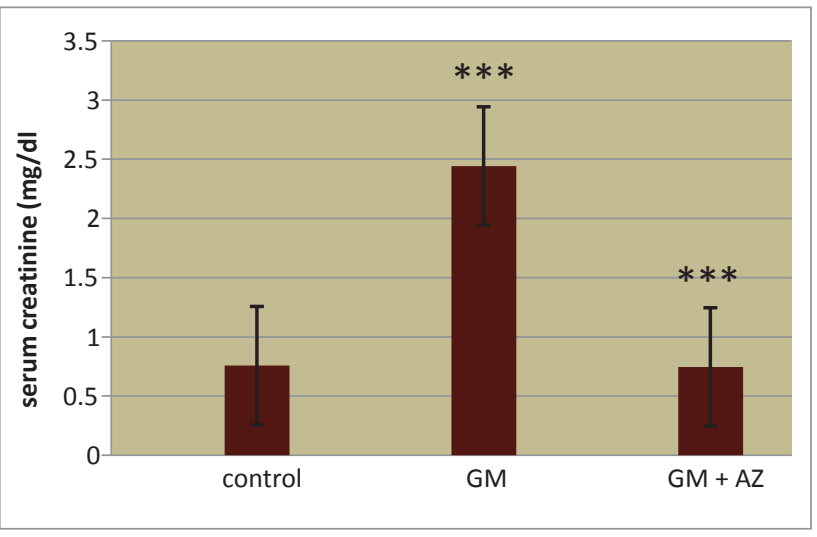

Figure 1: Graphic representation of effect of Adhatoda zeylanica at a dose of $500 \mathrm{mg} / \mathrm{kg}$ on serum urea (fig $1 \mathrm{~A}$ ) serum creatinine (fig 1B), and serum protein (1 C) in Gentamicin treated rats. $n=6$, values are expressed as Mean \pm S. E. M. $* p<0.05, * * p<0.01, * * * p<0.001, \mathrm{GM}=$ Gentamicin, AZ=Adhatoda zeylanica

Statistical Analysis : All values were expressed as Mean \pm SEM of two measurements. Comparison between standard
Figure: 2. Renal histology in the plain control group showing normal structure of kidney.

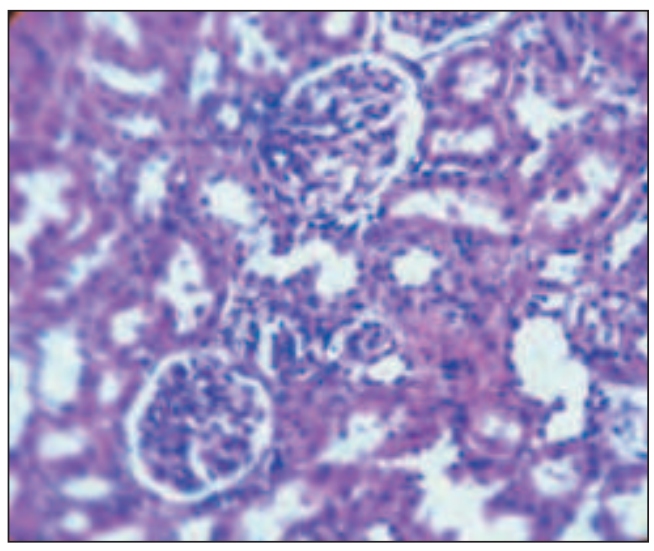

Figure: 3. Renal histology in negative control group showing severe tubular necrosis.

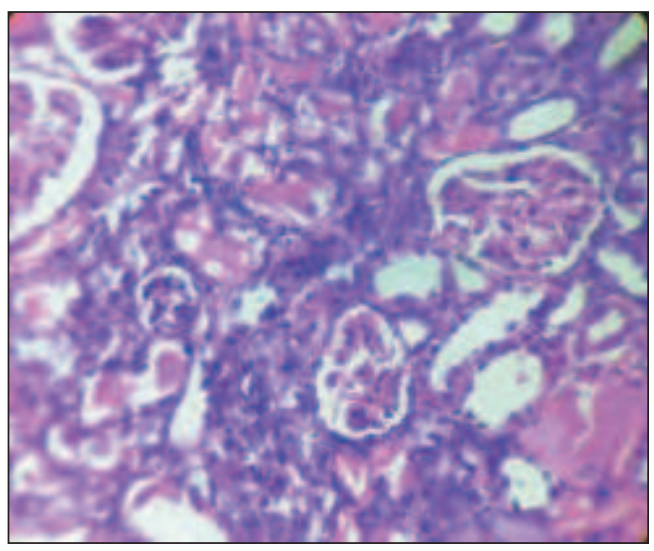

Figure: 4. Renal histology in post-treated group showing moderate tubular necrosis with reversal of inflammatory changes

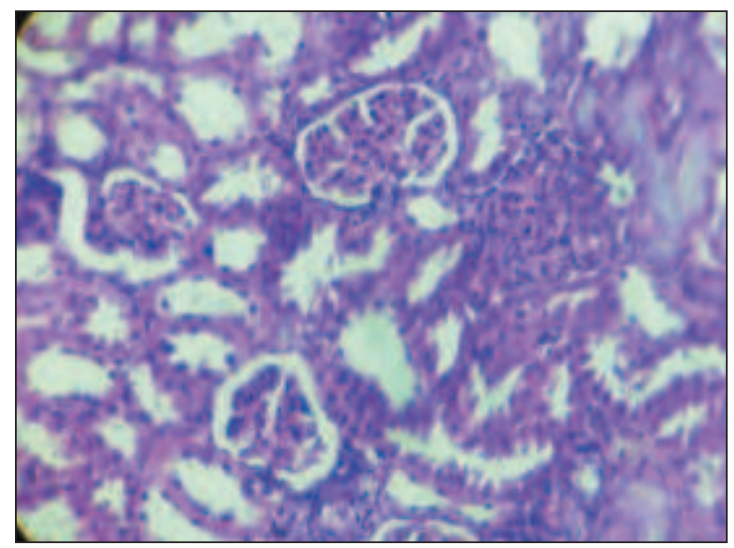

and extracts were performed by using Student's ' $t$ ' test. In all these tests, criterion for statistical significance was $\mathrm{P}<0.05$.

Histopathological examination: Control showed normal glomerular and tubular histology whereas Gentamicin 
group showed peritubular and blood vessel congestion and result presence of inflammatory cells in kidney section from the Gentamicin-treated group. Mononuclear cell infiltrated mainly in the sub capsular region and hyaline changes, vacuolization and necrosis in the proximal tubular epithelial cells was seen in Gentamicin group. Gentamicin group also showed interstitial edema in tubular cells. Concurrent treatment with the extract was found to reduce such changes in kidney histology induced by Gentamicin [Table II] Treatment with extracts could prevent cell damage such as tubular vacuolization, glomerular congestion and interstitial edema. According the pathological result it can be stated that ethanolic extract of Adathoda zeylanica has protective effect against degenerative injury caused by Gentamicin. Histolopathological changes are shown in Figure 2, Figure 3 and Figure 4.

Table II : Histopathological features of kidneys of rats of different treatement groups

\begin{tabular}{|l|c|c|c|}
\hline Histopathological features & Control & Gentamicin & $\begin{array}{c}\text { Gentamicin } \\
\text { and Adathoda } \\
\text { Zeylanica } \\
\text { treated group }\end{array}$ \\
\hline Glomerular congestion & - & +++ & ++ \\
\hline Peritubular congestion & - & +++ & ++ \\
\hline $\begin{array}{l}\text { Blood } \\
\text { vessel congestion }\end{array}$ & - & +++ & + \\
\hline Mononuclear infilteration & - & +++ & + \\
\hline Tubular casts & - & ++ & + \\
\hline
\end{tabular}

\section{Discussion :}

Adhatoda zeylanica (Acanthaceae) has a long history of use in traditional forms of oriental medicine and it has enjoyed popular use in India for a century. In addition, to its well known other activity, the plant has ability to remove reactive oxygen species and Gentamicin nephrotoxicity involves generation of ROS. The beneficial effect of $A$. Zeylanica against gentamicin nephrotoxicity possibly depends on its ability to scavenge the gentamicin induced free radicals.

The ethanolic extract from the leaves was evaluated for antioxidative potential using DPPH radical scavenging activity, hydroxyl radical scavenging activity and reducing power assay. In all these assays Ellagic acid, a potent free radical scavenging compound was used as the standard

The DPPH antioxidant assay is based on the ability of DPPH, a stable free radical, to decolorize in the presence of antioxidants. The DPPH radical contains an odd electron, which is responsible for the absorbance at $517 \mathrm{~nm}$ and also for visible deep purple color. When DPPH accepts an electron donated by an antioxidant compound, the DPPH is decolorized which can be quantitatively measured from the changes in absorbance.

Different studies have indicated that the electron donation capacity, reflecting the reducing power of bioactive compounds is associated with antioxidant activity [45]. The reducing ability of a compound generally depends on the presence of reductants, which have been exhibited antioxidative potential by breaking the free radical chain, donating a hydrogen atom. The presence of reductants (i.e. antioxidants) in Adathoda zeylanica leaves extracts causes the reduction of the $\mathrm{Fe}^{3+} /$ ferricyanide complex to the ferrous form. In this assay, yellow colour of the test solution changes to various shades of green and blue depending on the reducing power of antioxidant samples.

The measurement of $\mathrm{H}_{2} \mathrm{O}_{2}$ scavenging activity is one of the useful methods of determining the ability of antioxidants to decrease the level of pro-oxidants such as $\mathrm{H}_{2} \mathrm{O}_{2}$.[46] It can cross membranes and may slowly oxidize a number of compounds. Hydrogen peroxide itself is not very reactive, but sometimes it can be toxic to cells because of rise in the hydroxyl radicals in the cells [47]. In our study the results indicated that Adathoda zeylanica showed antioxidant activity compared with standard ellagic acid

In the present study, an effort has been made to examine the nephroprotective ability of ethanolic leaf extract of Adathoda zeylanica

Gentamicin is well recognized, to produce renal tubular necrosis mainly in the proximal tubule. This drug causes generation of reactive oxygen species (ROS), which induces 
cell injury and necrosis via lipid peroxidation $[48,49]$.

Our results clearly indicate that the gentamicin, at a dose of $80 \mathrm{mg} / \mathrm{kg} /$ day produces nephrotoxicity and it was evidenced by significant $(p<0.001)$ elevation the increased serum creatinine and serum urea and serum protein concentrations when compared with the plain control group suggesting impairment in glomerular function. Serum creatinine concentration is a more significant indicator than the serum urea concentration at an earlier phase of kidney disease. The ability of the kidney to filter creatinine (a non-protein waste product of creatinine phosphate metabolism) is reduced during renal dysfunction as a result of diminnished glomerular filteration rate. Thus, the increase in serum creatinine level is an indication of renal dysfunction [50]. The nephrotoxic effect was further corroborated by the histological findings in which many of the glomeruli showed diffuse eosinolphilc sclerosis, engorged blood vessels and areas of hemorrhage indicating severe tubular necrosis, while in plain control group normal histopathological features were seen. This functional and structural derangement caused by toxic agent is in agreement with other reports showing its nephrotoxic effects.

The progressive weight loss in gentamicin treated rats may possibly be due to the injury renal tubules and the subsequent loss of the tubular cells to reabsorb water, leading to dehydration and loss of body weight

The concurrent administration of Adhatoda zeylanica prevented the elevated level of serum creatinine and serum urea in albino rats administered gentamicin. Moreover, the elevated level of urinary protein was significantly reduced. These results suggest that Adhatoda zeylanica has an ability to prevent gentamicin-induced nephrotoxicity in albino rats.

Our results suggests that A. zeylanica at the dose used, was effective in mitigating the biochemical and histological changes induced by gentamicin. The nephrotoxic effects induced by gentamicin were significantly reversed. It is evident from the data that the effectiveness of the extract improved with the polarity of the solvents over a period of 10 days and the plant has the potential to ameliorate Gentamicin nephrotoxicity. The present study investigated the effect of Adhatoda zeylanica, in gentamicin-induced nephrotoxicity in albino rats. It may have potential to halt the development of Gentamicin induced nephrotoxicity in albino rats.

\section{Acknowledgements :}

The authors wish to thank the Research \& Recognition Committee of Nitte University, Mangalore, for funding this study.

\section{References:}

1. Hall JE. Text Book of Medical Physiology. $12^{\text {th }}$ ed. Philadelphia: Saunders Elsevier; 2011.p 307-326.

2. P faller W, Gstraunthaler G. Nephrotoxicity testing in vitro- what we know and what we need to know. Environ Health perspect 1998; 106(2):559-69.

3. Begum NA, Dewan ZF, Nahar N, Mamun MIR. Effect of $n$-Hexane extract of Nigella sativa on gentamicin induced nephrotoxicity in rats. Bangladesh J Pharmacol 2006; 1:16-20.

4. Han WK, Bonventre JV. Biologic markers for the early detection of acute kidney injury. Curr Opin Crit Care 2004;10:476-82.

5. Yaman I, Balikci E. Protective effects of Nigella sativa against gentamicin-induced nephrotoxicity in rats. Exp Toxicol Pathol 2010; 62(2):183-90.

6. Reiter RJ, Tan D, Sainz RM, Mayo JC, Lopez-Burillo S. Melatonin: reducing the toxicity and increasing the efficacy of drugs. J Pharm Pharmacol 2002; 54:1299-1321.

7. Sharma RK, Rajani GP, Sharma V, Komala N. Effect of ethanolic and aqueous extracts of Bauhinia Variegata Linn. on Gentamicin-Induced Nephrotoxicity in Rat. Ind J Pharm Edu Res 2011; 45(2):192-98.

8. Grover JK, Yadav S, Vats V. Medicinal plants of India with anti-diabetic potential. J Ethnopharmacol 2002; 81(1):81-100.

9. Aruoma Ol and Halliwell B (eds) (1998) Molecular Biology of Free Radicals in Human Diseases. St Lucia: OICA International Press.

10. Dizdaroglu $M$, Jaruga $P$, Birincioglu $M$, Rodriguez $\mathrm{H}$. Free radicalinduced damage to DNA: mechanisms and measurement. Free Radic Biol Med 2002; 32(11):1102-15.

11. Wilson RL. Free Radicals and Tissue Damage,Mechanistic Evidence from Radiation Studies. In: Biochemical Mechanisms of Liver Injury. Academic Press, New York 1988; pp.123

12. Maikhuri RK, Gangwar AK. Ethnobiological notes on the Khasi and Garo tribes of Meghalaya, Northeast India. Economic Botany 1993; 47: 345-57.

13. Dymock W, Waeden CJH, Hooper D. Pharmacographia Indica, A history of the principal drugs of vegetable origin. Paul, Trech, Trubner \& Co. Ltd, London 1890:50-54.

14. Kirtikar KR, Basu BD (1975) An, L.C.S., Indian Medicinal Plants 1975; Vol. 3, second ed. Bishen Singh Mahendra Pal Singh, Delhi. pp. 1899-1902.

15. Nadkarni KM. Indian Materia Medica, With Ayurvedic, Unani-Tibbi, Siddha, Allopathic,Homeopathic, Naturopathic \& Home Remedies, Appendices \& Indexes. Popular Prakashan, Bombay 1976:40-43.

16. Pushpangadan P, Nyman U, George V. Glimpses of Indian Ethnopharmacology. Tropical Botanic Garden and Research Institute, Kerala 1995:309-83.

17. Salalamp P, Chuakul W, Temsiririrkkul R, Clayton T. Medicinal Plants in Thailand. Amarin Printing and Publishing Public Co, Bangkok 1996:1; 21. 
18. Dymock W, Waeden CJH, Hooper D (1890) Pharmacographia Indica, A history of the principal drugs of vegetable origin. Paul, Trech, Trubner \& Co. Ltd, London. pp. 50-54.

19. Jain SP, Singh SC, Puri HS. Medicinal plants of Neterhat, Bibar, India. International Journal of Pharmacognosy 1994:32; 44-50.

20. Pathak RP (1970) Therapeutic Guide to Ayurvedic Medicine (A Handbook on Ayurvedic Medicine). Shri Ramdayal Joshi Memoria Ayurvedic Research Institute. Publ. Series No. 1, pp. 121, 208-209.

21. Pushpangadan P, Nyman U, George V (1995) Glimpses of Indian Ethnopharmacology. Tropical Botanic Garden and Research Institute, Kerala. pp 309, 383

22. Wren RC (1932) Potter's Cyclopædia of Botanical Drugs and Preparations, fourth ed. Potter \& Clarke, London. pp. 217

23. Madaus G (1938) Lehrbuch der Biologischen Heilmittel, Band II. Georg Thieme, Leipzig., pp. 1681-1684

24. Reddy MB, Reddy KR, Reddy MN. A survey of plant crude drugs of Anantapur district, Andhra Pradesh, India. International Journal of Crude Drug Research 1989:27; 145-155

25. Siddiqui MB, Husain W. Traditional treatment of gonorrhoea through herbal drugs in the province of central Uttar Pradesh, India. Fitoterapia 1993:64;399-403

26. Manandhar NP. Herbal remedies of Surkhet district, Nepal. Fitoterapia 1993:64; 266-72.

27. Arun K Yadav, Vareishang Tangpu. Anticestodal activity of Adhatoda vasica extract against Hymenolepis diminuta infections in rats. Journal of Ethnopharmacology 2008;119:322-24

28. Meenal Kumar, Ravindra Samarth, Madhu Kumar, Senthamil R.Selvan, Begraj Saharan, Ashok Kumar. Protective Effect of Adhatoda vascia Nees Against Radiation- Induced Damage at Cellular, Biochemical and Chromosomal Levels in Swiss Albino Mice. Evid Based Complement Alternat Med 2010; 4(3): 343-50.

29. Avula B, Begum S, Ahmed S, Choudhary M I, Khan I A. Quantitative determination of vasicine and vasicinone in Adhatoda vasica by high performance capillary electrophoresis. Pharmazie 2008; 63: 20-22.

30. Kumar A, Ram J, Samarth RM, Kumar M. Modulatory influence of Adhatoda vasica Nees leaf extract against gamma irradiation in Swiss albino mice. Phytomedicine 2005; 12(4):285-93.

31. G.Vinothapooshan, K.Sundar. leaves Hepatoprotective activity of Adathoda vasica against carbontetrachloride induced toxicity. Pharmacology online 2010;2: 551-58.

32. Shirish S. Pingale. Hepatosuppression by Adhatoda vasica against $\mathrm{CCl} 4$ Induced Liver Toxicity in Rat Pharmacologyonline 2009;3:633-39.

33. Wellwood JM, Lovell D, Thompson AE, et al., Renal damage caused by gentamicin. The Journal of Pathology 1976; 118(3):171-82

34. J. P. Moir, G. Viotte, A. Vandewalle, F.Van Hoof, Tulkens. Gentamicininduced nephrotoxicity A cell biology approach: Kidney International 1980;18:583-90

35. Porter GA, Laurent G, Maldague P, Tulkens P. Gentamicin-induced stimulation of DNA synthesis in rat kidney- Comparison between in vivo and in vitro model. Toxicol Lett 1984; 23(2):205-13.
36. Pramila Padmini M, Vijay Kumar J. A Histopathological Study on Gentamycin Induced Nephrotoxicity in Experimental Albino Rats. IOSR Journal of Dental and Medical Sciences 2012; 1(1):14-17.

37. Pratibha Singh, Man Mohan Srivastava, Lakhu Dev Khemani. Nephroprotective activities of root extracts of Andrographis paniculata (Burm f.) Nees in Gentamicin induced renal failure in rats: $A$ time-dependent study. Archives of Applied Science Research 2009; 1(2):67-73.

38. Laxmi B V S, Sudhakar M. Protective effect of Zingiber officinale on Gentamicin induced nephrotoxicity in rats. International Journal of Pharmacology 2010; 6(1):58-62.

39. Rama Saha1, SAR Choudhury. Gentamicin Induced Nephrotoxicity in Long Evans Rat - An Experimental Study. Bangladesh Journal of Anatomy 2009; 7: 84-86.

40. Okokon JE, Nwafor PA, Noah K. Nephroprotective effect of Croton zambesicus root extract against gentimicin-induced kidney injury. Asian Pac J Trop Med 2011; 4(12):969-72.

41. Hussain T, Gupta RK, Sweety K, Eswaran B, Vijayakumar M, Rao CV. Hussain T, Gupta RK, Sweety K, Eswaran B, Vijayakumar M, Rao CV. Nephroprotective activity of Solanum xanthocarpum fruit extract against gentamicin-induced nephrotoxicity and renal dysfunction in experimental rodents. Asian Pac J Trop Med 2012; 5(9):686-91.

42. Blois M.S, Antioxidant determinations by the use of a stable free radical. Nature 1958;2 9:1199-2000.

43. Elizabeth K, Rao MNA,Oxygen radical scavenging activity of curcumin. Int J Pharmaceut 1990; 58: 237-40.

44. Oyaizu M: Studies on products of browning reactions: antioxidant activities of products of browning reaction prepared from glucose amine. Jap J Nutr 1986; 44:307-15.

45. Siddhuraju P, Mohan PS, Becker K. Studies on the antioxidant activity of Indian laburnum (Cassia fistula L.): A preliminary assessment of crude extracts from stem bark, leaves, flowers and fruit pulp. Food Chem 2002; 79: 61-7.

46. Czochra MP, Widensk A. Spectrophotometric determination of hydrogen peroxide scavenging activity. J Anl Chemic ACTA 2002;452:177-84

47. Gulcin I. Antioxidant and antiradical activities of L- Carnitine. Life Sci 2006; 78: 803-11.

48. Stojiljkovic N, Veljkovic S, Mihailovic D, Stoiljkovic M, Radovanovic D, Randelovic P. The effect of calcium channel blocker Verapamil on gentamicin nephrotoxicity in rats. Bosn J Basic Med Sci 2008; 8(2):17076.

49. Perrrone RD, Madias NE, Levey AS. Serum creatinine as an index of renal function: new insights into old concepts. Clin Chem 1992; 38:1933-53

50. Silan C, Uzun O, Comunoglu NU, Gokcen S, Bedirhan S, Cengiz M . Gentamicin -induced nephrotoxicity in rats ameliorated and healing effects of Resveratrol. Biol. Pharm. Bull 2007; 30(3):79-83. 